\title{
The effects of society on the psychosocial functioning of those with a facial difference
}

\begin{abstract}
Adolescents with craniofacial conditions (CFCs) may experience intrapersonal and interpersonal challenges such as a greater sensitivity to attractiveness, fewer social supports, and more social withdrawal, all of which can hinder social interactions. However, there are contradictory findings as to whether adolescents with CFCs have more social problems than their peers. This article provides a framework for the social context of interpersonal relationships for those with CFCs drawn from relevant theoretical underpinnings. The authors conducted a comprehensive literature review examining social factors that affect the interpersonal functioning of adolescents with CFCs. Over 35 articles were taken from the growing, but limited, research on this topic via Psychlnfo and PubMed using specific search terms such as "craniofacial", "facial dysmorphisms", "complex facial dysmorphisms", "interpersonal", "psychosocial”, "social
\end{abstract}

functioning", and "adolescents" among others. Research has identified three salient barriers in social interactions: unattractive or inexpressive faces, social stigma, and societal misconceptions. The empirical studies reviewed postulate that having a facial difference does not result in social dysfunction, but rather the pressures and influences of society negatively impact social functioning. Based on the findings from this review, the authors propose a novel psychosocial model that explains the social dysfunction of adolescents with CFCs. Limitations and future interventions are also discussed.

\section{KEY WORDS}

psychosocial variables; social adjustment; chronic illness; social competencies

ORGANIZATION - Fordham University, New York, United States

AUthors' Contributions - A: Study design - B: Data collection - C: Statistical analysis - D: Data interpretation .

E: Manuscript preparation · F: Literature search · G: Funds collection

CORRESPONDING AUtHOR - Eric Riklin, Fordham University, 441 East Fordham Road, 10458 New York, United States,

e-mail: eriklin@fordham.edu

to CITE this ARTICLE - Riklin, E., Andover, M. S., \& Annunziato, R. A. (2019). The effects of society on the psychosocial

functioning of those with a facial difference. Health Psychology Report, 7(2), 87-102. https://doi.org/10.5114/

hpr.2019.85657

RECEIVED 02.03.2019 · REVIEWED 14.05.2019 • ACCEPTED 14.05.2019 · PUBLISHED 04.06.2019 


\section{BACKGROUND}

It is estimated that $2-3 \%$ of all infants worldwide (about 1 in every 1,600 births) are born with a craniofacial condition (CFC; WHO, 2003), which significantly affects their development and well-being throughout the lifespan. CFCs are defined as visible facial differences that are present at birth or develop over time due to injury or illness (Edwards, Topolski, Kapp-Simon, Aspinall, \& Patrick, 2011). It has been found that CFCs are caused not by one single factor, but rather a combination of multiple factors. Each CFC has its own etiology and, although some causes are still unknown, the most common etiological factors of CFCs include genetic factors, environmental factors, and folic acid deficiencies during pregnancy. Genetically speaking, CFCs could develop from a particular combination of gene(s) from one or both parents. It has been found that CFCs can arise when an individual inherits a disordered gene from one or both parents, or when they inherit multiple genes which, when combined, cause a craniofacial abnormality (Cohen, 2002; Murray, 2002). Additionally, changes in the genes at the time of conception could also result in a craniofacial difference. These mutations occur in different genes throughout the body, but the location of the gene is specific to different CFCs (Murray, 2002).

Given the genetic variability across these conditions, it can be difficult to obtain definitive genetic diagnoses. To combat these difficulties, studies have suggested the use of phenomic databases to help identify functional groups of genes (Birgfeld et al., 2011; Rahman \& Rahman, 2019; Roosenboom, Hens, Mattern, Shriver, \& Claes, 2016). Rahman and Rahman (2019) noted the benefits of gene-to-phenotype databases and niche expert phenomic resources to assist in clinical diagnosis and/or clinical management. Moreover, the authors suggest that certain predictive phenotypic tools (i.e., Phenolyzer and PHEVOR) provide additional information to enhance predictive capability. These tools can help expedite diagnostic clarity and provide education to clinicians, patients and families (Rahman \& Rahman, 2019). Certain CFCs have a wide phenotypic spectrum and, thus, these tools may be of particular importance. For example, Birgfeld et al. (2011) found that a phenotypic assessment tool for craniofacial microsomia provides a simple and standardized method to classify patients and can assist in evaluating the cause and background of the condition. Phenotype-genotype databases such as Online Mendelian Inheritance in Man (OMIM) also have been used to classify certain CFCs such as Treacher Collins syndrome (OMIM \#154500) and frontonasal dysplasia (OMIM \#136760; Roosenboom et al., 2016). Although there seems to be promise within these tools, other studies suggest that many methodological challenges still remain such as precise phenotyping techniques and efficient modeling methods (Roosenboom et al., 2016). The genetic complexity of CFCs makes it difficult to decipher the genotype-phenotype correlations in craniofacial morphology and, thus, more research is needed to determine these relationships.

Environmental factors may also play a role in the development of CFCs, especially in combination with genetic abnormalities. Although these factors are not fully understood, studies have shown that exposure to some drugs during pregnancy and certain prenatal environments can lead to different craniofacial abnormalities. For example, hemifacial microsomia has been linked to several drugs administered during pregnancy, including thalidomide (alleviates morning sickness), primidone (an anticonvulsant), and retinoic acid (assists with embryo development), and has also been linked to mothers who are diabetic (Cohen, 2002). Similarly, other studies have found that exposure to drugs such as phenytoin, valproic acid, and thalidomide can play a role in the development of cleft lip and/or palate (CL/P; Murray, 2002; Wyszynski \& Beaty, 1996). Research has suggested that other environmental factors include maternal alcohol or cigarette use (Beaty et al., 2001; Klingenberg et al., 2010; Little, Cardy, \& Munger, 2004; Romitti et al., 2007), low socioeconomic status (SES; Cembrano et al., 1995; Christensen, Schmidt, Vaeth, \& Olsen, 1995; Chung, Mi, \& Beechert, 1987), altitude at birth (Castilla, Lopez-Camelo, \& Campaña, 1999), and exposure to certain herbicides (García, Fletcher, Benavides, \& Orts, 1999) and infections (Natsume, Kawai, Ogi, \& Yoshida, 2000) prior to giving birth (Beaty et al., 2001; Murray, 2002; Wyszynski \& Beaty, 1996). These studies suggest that both ecological and environmental factors may play a role in the development of CFCs.

In addition to the environmental factors mentioned above, research has revealed that poor nutritional intake and vitamin deficiencies during pregnancy may also increase the risk of giving birth to a child with a craniofacial difference (Loffredo, Souza, Freitas, \& Mossey, 2001; Murray, 2002; Shaw, Lammer, Wasserman, O'Malley, \& Tolarova, 1995; Tolarova \& Harris, 1995; Wilcox et al., 2007). Folic acid has been one of the most widely studied vitamins in craniofacial research and folic acid deficiencies have been linked to the development of CFCs. Studies have found that women who do not take enough folic acid during pregnancy, or those who do not have enough folic acid in their diet, may have a greater risk of having a child with a CFC (Shaw et al., 1995; Tolarova \& Harris, 1995; Wilcox et al., 2007). Based on the literature, it is evident that poor nutrition and vitamin deficiencies, in combination with other environmental and genetic factors, all play a role in the development of CFCs. However, even with all of this knowledge on the etiology of CFCs, there are no cur- 
rent medical treatments for CFCs, with the standard of care being primarily surgical interventions.

It has been well established that those with CFCs experience a range of psychological problems, but the most common ones relate to social interactions (Bradbury, 2012; Edwards et al., 2005; Feragen \& Stock, 2017; Macgregor, 1990; Patrick et al., 2007; Robinson, Ramsey, \& Patridge, 1996; Strobel \& Renner, 2016; Topolski, Edwards, \& Patrick, 2005). Individuals with CFCs report difficulties with initial interactions, meeting new people, making friends, and developing relationships among others, and many attribute these problems to reactions or behaviors by the general public (Edwards et al., 2011; Feragen \& Stock, 2017; Macgregor, 1990; Masnari et al., 2013; Robinson et al., 1996; Strobel \& Renner, 2016). Research has shown that condition-specific effects or the severity of one's facial difference are not reliable predictors of childhood distress, whereas perceived stigmatization is a significant predictor of psychological adjustment and quality of life among youth with facial differences (Masnari et al., 2013).

Adolescence is emotionally challenging, and this can be amplified for those with CFCs (Bogart, 2015; Edwards et al., 2005; Feragen, Borge, \& Rumsey, 2009; Patrick et al., 2007; Roberts \& Shute, 2012; Topolski et al., 2005; Warschausky, Kay, Buchman, Halberg, \& Berger, 2002; Zulauf, Spinelli, \& Rosenberg, 2018) as it is a time of developmental growth and a heightened awareness of personal appearance and sense of self. Adolescents with CFCs are faced with difficult decisions about undergoing surgeries to improve their quality of life. Research has shown that some individuals experience emotional and social distress after surgery, possibly due to unmet or unrealistic expectations regarding their appearance and self-concept, which can affect psychological well-being (Bemmels et al., 2013; Bradbury, 2012; Edwards et al., 2005; Topolski et al., 2005; Zulauf et al., 2018). These negative perceptions not only affect one's quality of life and psychological functioning, but they also impact social functioning. Yet it also has been shown that some adolescents with a facial difference demonstrate considerable resiliency and are able to cope well in difficult situations (Beaune, Forrest, \& Keith, 2004; Bogart, 2015; Bradbury, 2012; Feragen et al., 2009; Feragen \& Stock, 2017). In this population, more research is needed to understand differential functioning for adolescents with CFCs as well as in comparison to those with other chronic health conditions or unaffected adolescents (Feragen \& Stock, 2017). Perhaps a major factor that influences such outcomes is the social context and how it is navigated. This review presents an overview of the psychosocial considerations for adolescents with CFCs and examine three main societal factors that can lead to social dysfunction and negative social interactions. The goal of this review is to identify pos- sible malleable areas for intervention for those who do experience compromised well-being that may be applicable to this population specifically but perhaps more broadly to other pediatric illnesses associated with visible manifestations of illness.

\section{METHOD}

This comprehensive literature review consisted of original, peer-reviewed articles examining social factors that affect the interpersonal functioning of adolescents with CFCs published between January 1990 and April 2019. Over 35 articles were taken from the growing, but limited, research on this topic via PsychInfo and PubMed due to their breadth of coverage. The authors used specific search terms relating to social functioning among adolescents with CFCs, such as "craniofacial", "facial dysmorphisms", "complex facial dysmorphisms", "interpersonal”, "psychosocial", "social functioning", and "adolescents" among others. All articles relating to all types of CFCs were included, but participants within each article were restricted to those 25 years old or younger (with the exception of a few studies noted in the body of this manuscript). Manuscripts using quantitative, qualitative, and mixed-methods designs were considered, and all methods of measurement (e.g., self-report, third-party reports, etc.) were included. No other exclusion criteria were imposed on the literature search.

\section{THEORETICAL UNDERPINNINGS}

Before discussing the reviewed literature, it is important to first explore sociological, sociocultural, and cognitive theories that may explain how individuals navigate their social worlds in general. Symbolic interactionism is a sociological theory that attempts to explain social interactions through the use of symbols (i.e., body language, physical attributes, spoken language, etc.), the assignment of meaning to those symbols, and the interpretation of actions based on the meaning of those symbols (Blumer, 1969). Based on this theory, symbols and meaning are subject to change and are formulated through one's previous experiences and social interactions. As individuals continue to interact with others, they learn more about the shared meaning that symbols have attached to them, which, in turn, shapes their own individual behavior based on this shared understanding within their social context (Blumer, 1969; Ratner, 1999). According to Goffman (1959), these modifications or alterations to behavior are a form of role-taking in which individuals play certain roles based on how they interpret others will view their behaviors in that particular situation and environment (a term that Goffman coined, dramaturgy). In an attempt to
Social dysfunction in those with CFCS 
Eric Riklin,

Margaret S.

Andover,

Rachel A.

Annunziato better understand a framework for cultural psychology by combining symbolic interactionism with activity theory (another approach to cultural psychology based on practical cultural activities), Ratner (1999) explains how these beliefs and behaviors are learned through repeated participation in social activities, embodied via characteristics of a particular social life, and then perpetuated through specific social relationships within their cultural context.

Similarly, from a cognitive perspective, social development theory suggests that social interaction plays a fundamental role in the development of cognition and individuals use tools that develop from their culture to mediate their social environments (Vygotsky, 1978). According to Vygotsky (1978), internalization of these tools leads to higher thinking skills and one's level of cognitive development depends on the level of social interaction. This transactional view (i.e., the interaction between the individual, their environment, and others in the environment) has profound implications for the conceptualization of the development of representational constructs, such as social schemas (McVee, Dunsmore, \& Gavalek, 2005). Social schema theory posits that mental representations (i.e., schemas) are organized and stored within one's mind to better understand thoughts, behaviors, concepts, and other information and the relationships among them (Aronson, Wilson, \& Akert, 2010). When schemas are activated, individuals form judgments based on previous experiences that influence social cognitions and behaviors, regardless of whether those judgments are accurate (Aronson et al., 2010). Given that social and cultural tools mediate learning and development, social and cultural considerations are essential factors in schema acquisition (McVee et al., 2005). Therefore, the content of schemas differs based on one's cultural upbringing and relationship with social norms (Aronson et al., 2010). Taken together, all of these theories provide a foundational understanding of how those with CFCs navigate difficult social interactions as they too must endure various interpretations of others based on the meaning of diverse symbols, specific sociocultural characteristics of their environment, and the formation of social schemas.

\section{PSYCHOSOCIAL FUNCTIONING}

Studies examining the quality of life, self-perception, psychosocial adjustment, and social skills development among adolescents with CFCs have found that those who report adjustment problems attribute these to difficulties in social situations (Beaune et al., 2004; Bessell et al., 2012; Bradbury, 2012; Feragen et al., 2009; Feragen \& Stock, 2017; KappSimon, McGuire, Long, \& Simon, 2005; Patrick et al., 2007; Topolski et al., 2005; Warschausky et al., 2002).
Topolski et al. (2005) examined the self-perceptions of adolescents, aged 11-18, with CFCs $(n=56)$ by comparing their self-reported quality of life to that of adolescents with mobility limitations $(n=52)$, adolescents with attention deficit hyperactivity disorder (ADHD) $(n=68)$, with other health conditions and adolescents with no diagnosed chronic condition $(n=116)$. Those with facial differences were found to have lower overall quality of life than those without a chronic condition, and those with facial differences tended to feel less safe in school and reported less satisfaction with peer relationships than those not diagnosed with a chronic condition (Topolski et al., 2005; see Table S1).

Additionally, those with CFCs have less positive social support, less social interaction, and more social withdrawal than the general public due to a greater sensitivity to attractiveness and lower quality of life (Edwards et al., 2011; Feragen et al., 2009). Many adolescents with CFCs turn to social withdrawal and isolation in order to avoid painful social interactions. This lack of social exposure can lead to fewer opportunities to develop social skills and hinder social adjustment (Robinson et al., 1996). Robinson et al. (1996) discuss a "negative social interaction cycle" whereby adolescents who are socially isolated become shyer or defensive, which, in turn, decreases their chance of forming positive relationships with their peers (p. 281; see Table S1). As this cycle continues and the number of negative social interactions increases, it becomes more difficult for individuals with CFCs to maintain and develop relationships, which negatively affects their self-concept and self-satisfaction and can lead to feelings of incompetence and loneliness, and challenges with emotional expression and social anxiety (Bessell et al., 2012; Bradbury, 2012; Crerand, Sarwer, Kazak, Clarke, \& Rumsey, 2017; Kapp-Simon et al., 2005; Pierpont, Semrud-Clikeman, \& Pierpont, 2017; Robinson et al., 1996).

With this in mind, it is important to understand the reasons behind these negative social interactions in order to better serve this population. The aforementioned social interaction theories provide a basic understanding of how individuals navigate social interactions, but they do not fully explain the specific difficulties faced by those with CFCs. Research has delineated three salient barriers to improving social interactions among those with CFCs: unattractive or inexpressive faces, social stigma, and societal misconceptions. These three factors may be applicable to any adolescent with a health or mental health condition (e.g., teens with significant acne or adolescents with autism spectrum disorder who have social skills deficits), but their impact on well-being may be unique to adolescents with CFCs. Below, the data in support of and implications stemming from this conceptualization are presented. Table S1 provides additional information for studies that informed this framework. 


\section{PERCEPTIONS OF ATTRACTIVENESS AND FACIAL EXPRESSIONS}

It has been well established that faces provide emotional and social information about one's affective state and behaviors that elicit specific responses in others (Bradbury, 2012; Edwards et al., 2011; Masnari et al., 2013; Zebrowitz \& Montepare, 2008). Facial cues and appearance can impact social interactions such that those who are viewed as more attractive are generally viewed in a more favorable light (e.g., more outgoing, socially competent, intelligent; Zebrowitz \& Montepare, 2008). Those with CFCs appear to be at a disadvantage since studies have shown that looking different or having a stigmatizing health condition affects social responses (Bogart, Tickle-Degnen, \& Joffe, 2012; Bogart, 2015; Bradbury, 2012; Edwards et al., 2011; Rumsey \& Harcourt, 2005; Strobel \& Renner, 2016; Zebrowitz \& Montepare, 2008). These individuals are perceived to have lower social competence, and others view their interactions with them more negatively and anticipate more negative social outcomes. Edwards et al. (2011) conducted an observational study examining the association between first impressions and social skills among young adults, ages 11-18, with CFCs (see Table S1). After viewing 1-minute video portrayals of positive and negative social skills by actors with CFCs, researchers asked adolescents with $(n=29)$ and without $(n=31)$ CFCs, adults $(n=40)$, medical students $(n=46)$, and education students $(n=29)$ to rate their perceptions of the actors' attributes using the First Impressions Rating Scale (FIRS; Edwards et al., 2011). It was found that those who portrayed negative social skills were rated more negatively than those who portrayed positive social skills (i.e., viewed as more untrustworthy, rude, insensitive, unfriendly, unpleasant, unattractive, unpopular, stupid, etc.; Edwards et al., 2011). Additionally, only vignettes portraying negative social skills resulted in greater facial difference severity, whereas vignettes portraying positive social skills had little effect on this measure, suggesting an association between negative social skills and how severe one perceives an individual's facial difference (Edwards et al., 2011).

Zebrowitz and Montepare (2008) propose an "anomalous face overgeneralization" to explain this phenomenon, which states that humans have evolutionarily-adapted to recognize individuals with diseases or bad genes and perceive them more negatively since it has become adaptive to categorize them as unfit or unhealthy (Zebrowitz \& Montepare, 2008, p. 3). From a cultural perspective, having a scarred or deformed face can be representative of "evil" throughout different cultures, whereas having a symmetrical or undistorted face can be representative of goodness (Bradbury, 2012). In these particular cultures, children are taught these lessons early, which is, in turn, reinforced in adult culture (Rumsey \& Harcourt, 2005). As evidenced above, various sociocultural and cognitive theories have suggested that these beliefs are learned through repeated sociocultural activities and maintained through social relationships, specific cultural characteristics, and the development of social schemas (Blumer, 1969; Goffman, 1959; McVee et al., 2005; Ratner, 1999; Vygotsky, 1978). Thus, individuals with a CFC may be predisposed to negative social interactions due to others' learned perceptions of their unattractiveness.

Facial expressions help us communicate emotion, understand the dynamics of conversation, develop rapport, and build social connectedness (Zebrowitz \& Montepare, 2008). Those with CFCs may have an added disadvantage in social situations since they may have facial paralysis which limits their facial expressions. Not all individuals with CFCs have facial palsy, but specific CFCs are characterized by facial palsy (e.g., Moebius syndrome) while other individuals may develop facial paralysis after surgery (Bemmels et al., 2013; Bogart et al., 2012; Bogart, 2015; Strobel \& Renner, 2016). Studies have found that blunted expression of affect can negatively affect social interactions. Others tend to form inaccurate impressions of those who lack facial expressions such that they are perceived as apathetic, insensitive, unfriendly, and unintelligent (Bogart et al., 2012; Bogart, 2015; Bradbury, 2012; Hemmesch, Tickle-Degnen, \& Zebrowitz, 2009; Tickle-Degnen \& Lyons, 2004). Tickle-Degnen and Lyons (2004) examined medical practitioners' use of facial cues to form accurate impressions of people with Parkinson's disease, a disorder that can consist of an inability to control the face and mouth, and concluded that those with more limited facial expressions are perceived more negatively than those with less limited facial expressions (see Table S1). Due to their diminished expressivity, others may not view those who lack facial expressions as good social partners, which may decrease the likelihood that others would want to pursue friendships with them and negatively affect relationships (Bogart et al., 2012; Bogart, 2015; Hemmesch et al., 2009). Since individuals with CFCs can have limited facial expressions, it is possible that their interpersonal relationships are also affected by others' misinterpretations of facial affect.

\section{SOCIAL STIGMA}

A second barrier to social interactions is the impact of social stigma on CFCs. As outlined by Goffman (1963), social stigma is a phenomenon in which an individual is rejected by their society as a result of an attribute which is discredited or classified as undesirable by other members of that society. He suggests that this stigma can result in increased feelings of
Social dysfunction in those with CFCs 
Eric Riklin,

Margaret S.

Andover,

Rachel A.

Annunziato shame because individuals feel as though they have failed to meet other people's standards and, thus, the reaction of others spoils their identities (Goffman, 1963). As faces are considered a salient symbol of identity (Goffman, 1963), those with CFCs are particularly subject to stigma given that their faces are visibly different. Edwards and colleagues (2011) further discuss the construct of social stigma in relation to those with CFCs (see Table S1). They define social stigma as "negative attributions others make based upon a visible mark that distinguishes an individual as different from others", as well as "when the individual directly experiences the manifest effects of stigma, such as discrimination, rejection, or physical abuse", both of which are relevant in this context (Edwards et al., 2011, p. 91). The social meaning given by others of the disfigurement can result in different responses (e.g., fear, pity, or disgust), all of which can influence one's ability to cope (Bradbury, 2012). As previously mentioned, individuals with CFCs are at risk for teasing and bullying, which can negatively impact their psychosocial functioning (Beaune et al., 2004; Bradbury, 2012; Edwards et al., 2011; Feragen et al., 2009; Feragen \& Stock, 2017; Hunt, Burden, Hepper, Stevenson, \& Johnston, 2006; Kapp-Simon et al., 2005; Masnari et al., 2013). Feragen and Stock (2017) conducted a systematic review examining the impact of CFCs on several domains of functioning and found that $40 \%$ of children, adolescents, and young adults with craniosynostoses reported experiences of teasing and bullying, while only $20.1 \%$ of matched controls reported experiencing social stigma (see Table S1). Their review suggests that children and adolescents with CFCs experience higher frequencies of teasing compared to control groups (Boltshauser, Ludwig, Dietrich, \& Landholt, 2003; Feragen \& Stock, 2017; Fischer et al., 2014).

Studies by Hunt et al. (2006) and Feragen et al. (2009) examined psychosocial functioning and selfreported social experiences of youth with $\mathrm{CL} / \mathrm{P}$ (see Table S1). One cross-sectional study by Hunt et al. (2006) compared the psychosocial functioning of 160 children and young adults with and without CL/P and 113 unaffected children and young adults. It was found that being teased or bullied was a significant predictor of poor psychological functioning, greater behavioral problems, and greater dissatisfaction with facial appearance, whereas having $\mathrm{CL} / \mathrm{P}$ was not predictive of these outcomes (Hunt et al., 2006). These findings suggest that external factors, such as teasing, bullying, and other forms of discrimination, may have more of an impact on psychosocial dysfunction than the presence of the CFC itself.

Feragen et al. (2009) further examined self-reported social experiences of those with $\mathrm{CL} / \mathrm{P}$. Their cross-sectional study investigated various factors that might affect the psychosocial resilience of 268 children born with $\mathrm{CL} / \mathrm{P}$, such as cognitive, emo- tional, and psychosocial functioning, satisfaction with appearance, and reported teasing or staring. It was found that lower psychosocial resilience was associated with lower satisfaction with appearance and more reports of teasing or staring (Feragen et al., 2009). Based on their results, the authors suggest that greater social stigma and lower satisfaction with appearance may be linked to greater dissatisfaction with social experiences and greater social maladjustment due to lower psychosocial resilience (Feragen et al., 2009). Findings from both of these studies show that social stigma, as opposed to the presence of the CFC itself, not only negatively affects the psychosocial functioning of those with a CFC but may also impact their resilience and prevent them from effectively coping with negative social interactions.

\section{SOCIETAL AWARENESS AND UNDERSTANDING}

Related to social stigma, a lack of understanding of these conditions by the general public may also impact interactions. Since CFCs are so rare, it is not surprising that the public is unfamiliar with these conditions. Studies have found that people with other visible health conditions, such as those undergoing cancer treatment or those who are blind, are generally viewed with compassion and support and are viewed more positively due to the public's familiarity with the conditions and their treatments (Rowland \& Bell, 2012; Snyder \& Pearse, 2010; Yoo, Aviv, Levine, Ewing, \& Au, 2010). In contrast to these visible differences, when someone encounters an individual with a CFC, they may react negatively because they are unsure of how to act around them (Beaune et al., 2004; Bogart et al., 2012; Bogart, 2015; Joachim \& Acorn, 2003).

Joachim and Acorn (2003) conducted focus groups with individuals with scleroderma, a rare, chronic connective tissue disease, in order to better understand the experiences of someone living with a rare disease (see Table S1). Although scleroderma is not necessarily categorized as a CFC, both types of conditions are rare diagnoses that affect one's outward appearance and are not fully understood by the general public. This study found that participants felt stigmatized by others because their condition was so rare that people did not understand their appearance or how to interact with them. Similarly, Bogart et al. (2012) conducted focus groups to examine the social interactions of individuals with Moebius syndrome (MoS), a rare, congenital CFC characterized by facial paralysis. Participants identified stigma and public awareness (or lack of awareness) as two of the main themes affecting their social functioning. Several participants mentioned that they felt as though others viewed them as having an intellectual disability 
because of the way they looked and communicated, making it difficult to interact with them, while others stated that they felt uncomfortable having to share personal information just because others required an explanation (see Table S1). Beaune et al. (2004) used semistructured interviews and other qualitative techniques to explore the experiences of adolescents, aged 12-18, with Treacher Collins syndrome (TCS; see Table S1). They found that participants frequently experienced overt, as well as subtle, uncomfortable social interactions due to the unfamiliarity of their difference. However, the adolescents noted that as others got to know them and better understand their differences and abilities, their peers were able to move past their negative stereotypes and were generally more accepting of them. The barriers found to be affecting the social interactions of the individuals in these studies were not internal barriers, but rather external societal factors.

\section{CONCLUSIONS}

It is clear that many adolescents with CFCs have difficulties in social interactions, but as evidenced by this review, a significant body of literature suggests that having a facial difference does not result in social dysfunction, but rather the pressures and influences of society negatively impact social functioning. Based on the findings from this review and the relevant theoretical underpinnings mentioned above, the following proposed psychosocial model explains the social dysfunction of adolescents with CFCs (see Figure 1) to be tested via future longitudinal work. Research suggests that others' perceptions of attractiveness and facial expressiveness, teasing and bullying, and society's limited understanding of facial differences all play a role in affecting the so- cial interactions of those with CFCs. These negative social interactions lead to negative self-perceptions and poor social skills among adolescents with a facial difference, which results in problems in their social functioning. Taken together, it would seem as though most of the poor social interactions, negative self-perceptions, and social dysfunction are caused by external factors as opposed to the CFC itself. This proposed model provides a first look into the effects of society on the psychosocial functioning of those with CFCs, which could help aid in the development of possible interventions for this population.

The present review offers individual-level, malleable treatment targets as well. Social skills training may be most directly impactful in helping those with CFCs navigate the challenges described here. Several studies have suggested that interventions focused on increasing psychoeducation and bolstering social skills and social support could improve the ability to cope in difficult social situations and negate these negative external factors (Bessell et al., 2012; Bogart, 2015; Bradbury, 2012; Feragen et al., 2009; Kapp-Simon et al., 2005; Masnari et al., 2013; Patrick et al., 2007; Robinson et al., 1996; Spinelli, 2004; Strobel \& Renner, 2016; Topolski et al., 2005; Zulauf et al., 2018). Enhancing social support can help reduce potential stigma and promote overall coping, and this can become increasingly important as the individual progresses through adolescence (Zulauf et al., 2018). In terms of social skills, Kapp-Simon et al. (2005) investigated the effect of social skills training on social interactions among adolescents with CFCs (see Table S1). Participants were enrolled in either a treatment condition or a notreatment control condition. Those in the treatment group underwent a 12-week social skills training program designed to improve social and emotional functioning. The results indicated that those in social skills training had a greater increase in overall rate of
Social dysfunction in those with CFCs

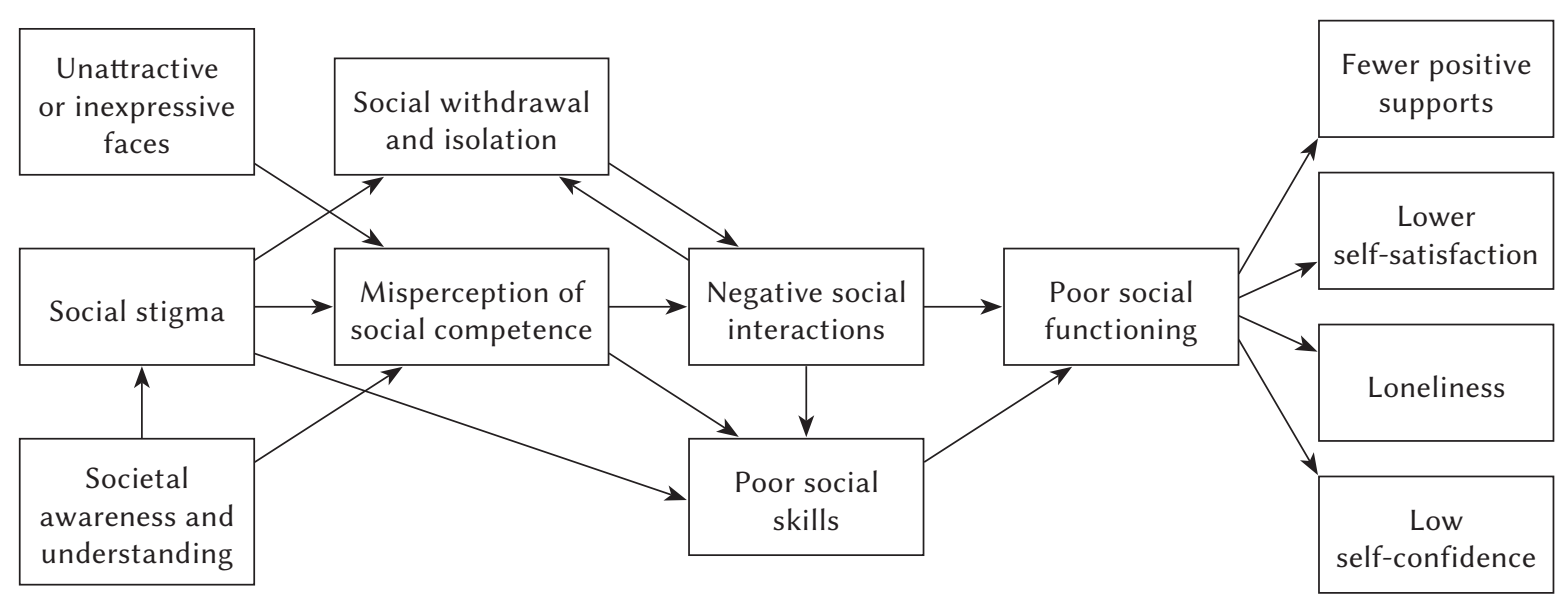

Figure 1. Psychosocial model of social dysfunction among adolescents with CFCs. 
Eric Riklin,

Margaret S.

Andover,

Rachel A.

Annunziato social interactions. In fact, adolescents in the treatment group were three times more likely to engage in a conversation with their peers than they were before starting the group. Findings from this study suggest that social skills training would be beneficial for those with CFCs and future interventions should consider adopting these strategies.

Given that the external factors mentioned in this review are more difficult to address in treatment, cognitive restructuring may also be a viable treatment target for this population. Bessell et al. (2012) took this a step further and examined the effects of a computer-based CBT intervention designed to reduce anxiety, depression, and appearance concerns, and improve psychological adjustment (see Table S1). Eighty-three adults with a visible difference (i.e., CFCs, skin conditions, facial and body scarring, etc.) were randomized to three different groups: a new computerized intervention (Face It) that incorporates social skills training, exposure-based treatment for overcoming anxiety, and cognitive restructuring; a face-to-face intervention that included identical content to the computer-based group; and a control condition that was considered treatment as usual with the addition of completing standard measures. Participants across all three groups completed psychological questionnaires at pre-intervention, postintervention, and at 3-month and 6-month followups. The study found that those in the face-to-face intervention and computer-based groups displayed significant reductions in anxiety, depression, appearance-related distress, and fear of negative evaluations when compared to the control group (Bessell et al., 2012). Interestingly, all improvements were maintained at both follow-up time points, suggesting that participants experienced increased positive adjustment over time. In addition, there was an improvement in body image quality of life in the faceto-face group, but not the computer-based group, suggesting that face-to-face delivery may be more effective than computer delivery (Bessell et al., 2012). Findings from this study suggest that social skills training, along with cognitive restructuring and exposure therapy (e.g., being exposed to negative social interactions), may be beneficial in reducing distress and anxiety, and improving psychological well-being in those with a facial difference.

In conducting the present review, several limitations were uncovered. The majority of studies reviewed in this paper were cross-sectional and relied on self-report. Given the interaction between psychological adjustment measured as an outcome and as an ongoing social experience, these types of studies make it harder to draw accurate conclusions about the relationship between CFCs and external factors. It is very possible that the findings from these studies are more related to satisfaction with appearance as opposed to other external factors and, thus, misrepresent the impact of social factors on the social functioning of those with CFCs. Additionally, there is a question of sample size and homogeneity within these studies, making it difficult to generalize the findings to the larger population. Moreover, given that the majority of these studies assessed CFCs as a whole and did not differentiate between specific conditions, it is difficult to determine the effects of these societal factors on different conditions and, thus, severity may range depending on the type of CFC. Future reviews should attempt to include a greater number of studies that vary in study design, sample characteristics, and methodology (e.g., experimental, longitudinal, or observational studies). Furthermore, while the three barriers mentioned in this review are important to consider, there are other external factors and internal characteristics that may affect social functioning. For example, neurocognitive functioning, impaired mobility, physiological features, and socioeconomic status may all play a role in an individual's social impairment, but they were not considered in the proposed model. Similarly, those with CFCs can also have comorbid diagnoses which may further impact their social relations and/or interactions. It would be important for future studies to further examine these other factors in order to integrate them into this model and guide future research. Given these limitations, it is difficult to draw conclusions about the extent to which social factors affect the psychosocial functioning of adolescents with CFCs.

In conclusion, more research is needed to demonstrate the utility of the proposed model and to explore the use of other interventions that may directly tackle interpersonal concerns in this population. Future research should also include more heterogeneous samples and a broader assessment of functioning to further understand the effects of poor psychosocial adjustment on the general craniofacial population. This new information could assist in developing and refining useful programs or interventions for this population that aim to improve social functioning and the overall psychological well-being of adolescents with CFCs as well as more generally in pediatric and adolescent medicine settings.

\section{References}

Aronson, E., Wilson, T. D., \& Akert, R. M. (2010). Social psychology (7th ed.). Upper Saddle River, NJ: Pearson.

Beaty, T. H., Wang, H., Hetmanski, J. B., Fan, Y. T., Zeiger, J. S., Liang, K. Y., Chiu, Y. F., Vanderkolk, C. A., Seifert, K. C., Wulfsberg, E. A., Raymond, G., Panny, S. R., \& McIntosh, I. (2001). A case-control study of nonsyndromic oral clefts in Maryland. Annals of Epidemiology, 11, 434-442. https://doi.org/10.1016/ S1047-2797(01)00222-8 
Beaune, L., Forrest, C. R., \& Keith, T. (2004). Adolescents' perspectives on living and growing up with Treacher Collins syndrome: a qualitative study. The Cleft Palate-Craniofacial Journal, 41, 343-350. https://doi.org/10.1597/02-158.1

Bemmels, H., Biesecker, B., Schmidt, J. K., Krokosky, A., Guidotti, R., \& Sutton, E. J. (2013). Psychological and social factors in undergoing reconstructive surgery among individuals with craniofacial conditions: An exploratory study. The Cleft Palate-Craniofacial Journal, 50, 158-167. https://doi.org/10.1597/11-127

Bessell, A., Brough V., Clarke, A., Harcourt, D., Moss, T. P., \& Rumsey, N. (2012). Evaluation of the effectiveness of Face IT, a computer-based psychosocial intervention for disfigurement-related distress. Psychology, Health \& Medicine, 17, 565-577. https://doi.org/10.1080/13548506.2011.647701

Birgfeld, C. B., Luquetti, D. V., Gougoutas, A. J., Bartlett, S. P., Low, D. W., Sie, K. C., Evans, K. N., \& Heike, C. L. (2011). A phenotypic assessment tool for craniofacial microsomia. Plastic and Reconstructive Surgery, 127, 313-320. https://doi.org/10.1097/ PRS.0b013e3181f95d15

Blumer, H. (1969). Symbolic interactionism: Perspective and method. Englewood Cliffs, NJ: Prentice-Hall.

Bogart, K. R. (2015). "People are all about appearances": A focus group of teenagers with Moebius syndrome. Journal of Health Psychology, 20, 15791588. https://doi.org/10.1177/1359105313517277

Bogart, K. R., Tickle-Degnen, L., \& Joffe, M. S. (2012). Social interaction experiences of adults with Moebius Syndrome: A focus group. Journal of Health Psychology, 17, 1212-1222. https://doi.org/10.1177/ 1359105311432491

Boltshauser, E., Ludwig, S., Dietrich, F., \& Landolt, M. A. (2003). Sagittal craniosynostosis: cognitive development, behaviour, and quality of life in unoperated children. Neuropediatrics, 34, 293-300. https://doi. org/10.1055/s-2003-44667

Bradbury, E. (2012). Meeting the psychological needs of patients with facial disfigurement. British Journal of Oral and Maxillofacial Surgery, 50, 193-196. https://doi.org/10.1016/j.bjoms.2010.11.022

Castilla, E. E., Lopez-Camelo, J. S., \& Campaña, H. (1999). Altitude as a risk factor for congenital anomalies. American Journal of Medical Genetics, 86, 9-14. https://doi.org/10.1002/(SICI)1096-8628 (19990903)86:1<9::AID-AJMG3>3.0.CO;2-X

Cembrano, J. R., De Vera, J. S., Joaquino, J. B., Ng, E. F., Tongson, T. L., Manalo, P. D., Fernandez, G. C., \& Encarnacion, R. C. (1995). Familial risk of recurrence of clefts of the lip and palate. Philippine Journal of Surgical Specialties, 50, 37-40.

Christensen, K., Schmidt, M. M., Vaeth, M., \& Olsen, J. (1995). Absence of an environmental effect on the recurrence of facial-cleft defects. The New England Journal of Medicine, 333, 161-164. https://doi. org/10.1056/NEJM199507203330305
Chung, C. S., Mi, M. P., \& Beechert, A. M. (1987). Genetic epidemiology of cleft lip with or without cleft palate in the population of Hawaii. Genetic Epidemiology, 4, 415-423. https://doi.org/10.1002/ gepi. 1370040603

Cohen, M. M. Jr. (2002). Malformations of the craniofacial region: Evolutionary, embryonic, genetic, and clinical perspectives. American Journal of Medical Genetics, 115, 245-268. https://doi.org/10.1002/ ajmg. 10982

Crerand, C. E., Sarwer, D. B., Kazak, A. E., Clarke, A., \& Rumsey, N. (2017). Body image and quality of life in adolescents with craniofacial conditions. The Cleft Palate-Craniofacial Journal, 54, 2-12. https://doi.org/10.1597/15-167

Edwards, T. C., Patrick, D. L., Topolski, T. D., Aspinall, C. L., Mouradian, W. E., \& Speltz, M. L. (2005). Approaches to craniofacial-specific quality of life assessment in adolescents. The Cleft Palate-Craniofacial Journal, 42, 19-24. https://doi.org/10.1597/03-097.2.1

Edwards, T. C., Topolski, T. D., Kapp-Simon, K. A., Aspinall, C. L., \& Patrick, D. L. (2011). What difference can a minute make? Social skills and first impressions of youth with craniofacial differences. The Cleft Palate-Craniofacial Journal, 48, 91-97. https://doi.org/10.1597/08-204

Feragen, K. B., Borge, A. I., \& Rumsey, N. (2009). Social experience in 10-year-old children born with a cleft: Exploring psychosocial resilience. The Cleft Palate-Craniofacial Journal, 4, 65-74. https://doi. org/10.1597/07-124.1

Feragen, K. B., \& Stock, N. M. (2017). Psychological adjustment to craniofacial conditions (excluding oral clefts): A review of the literature. Psychology \& Health, 32, 253-288. https://doi.org/10.1080/088 70446.2016.1247838

Fischer, S., Tovetjarn, R., Maltese, G., Sahlin, P. E., Tarnow, P., \& Kolby, L. (2014). Psychosocial conditions in adults with Crouzon syndrome: A followup study of 31 Swedish patients. Journal of Plastic Surgery and Hand Surgery, 48, 244-247. https://doi. org/10.3109/2000656x.2013.868811

García, A. M., Fletcher, T., Benavides, F. G., \& Orts, E. (1999). Parental agricultural work and selected congenital malformations. American Journal of Epidemiology, 149, 64-74. Retrieved from https:// academic.oup.com/aje/article-pdf/149/1/64/535 036/149-1-64.pdf

Goffman, E. (1959). The presentation of self in everyday life. New York, NY: Anchor Books.

Goffman, E. (1963). Stigma: Notes on the management of spoiled identity. New York, NY: Simon \& Schuster, Inc.

Hemmesch, A. R., Tickle-Degnen, L., \& Zebrowitz, L. A. (2009). The influence of facial masking and sex on older adults' impressions of individuals with Parkinson's disease. Psychology and Aging, 24, 542-549. https://doi.org/10.1037/a0016105
Social dysfunction in those with CFCs 
Hunt, O., Burden, D., Hepper, P., Stevenson, M. \& Johnston, C. (2006). Self-reports of psychosocial functioning among children and young adults with cleft lip and palate. The Cleft Palate-Craniofacial Journal, 43, 598-605. https://doi.org/10.1597/05-080

Joachim, G., \& Acorn, S. (2003). Life with a rare chronic disease: The scleroderma experience. Journal of Advanced Nursing, 42, 598-606. https://doi. org/10.1046/j.1365-2648.2003.02663.x

Kapp-Simon, K. A., McGuire, D. E., Long, B. C., \& Simon, D. J. (2005). Addressing quality of life issues in adolescents: Social skills interventions. The Cleft Palate-Craniofacial Journal, 42, 45-50. https://doi. org/10.1597/03-0976.1

Klingenberg, C. P., Wetherill, L., Rogers, J., Moore, E., Ward, R., Autti-Rämö, I., Fagerlund, Å., Jacobson, S. W., Robinson, L.K., Hoyme, H. E., Mattson, S. N., Li, T. K., Riley, E. P., Foroud, T., \& CIFASD Consortium. (2010). Prenatal alcohol exposure alters the patterns of facial asymmetry. Alcohol, 44, 649657. https://doi.org/10.1016/j.alcohol.2009.10.016

Little, J., Cardy, A., \& Munger, R. G. (2004). Tobacco smoking and oral clefts: A meta-analysis. Bulletin of the World Health Organization, 82, 213-218. http:// dx.doi.org/10.1590/S0042-96862004000300011

Loffredo, L. C., Souza, J. M., Freitas, J. A., \& Mossey, P. A. (2001). Oral clefts and vitamin supplementation. The Cleft Palate-Craniofacial Journal, 38, 76-83. https:// doi.org/10.1597/1545-1569(2001)038<0076:OCAVS> 2.0.CO;2

Macgregor, F. C. (1990). Facial disfigurement: Problems and management of social interaction and implications for mental health. Aesthetic Plastic Surgery, 14, 249-257. https://doi.org/10.1007/BF01578358

Masnari, O., Schiestl, C., Rössler, J., Gütlein, S. K., Neuhaus, K., Weibel, L., Meuli, M., \& Landolt, M. A. (2013). Stigmatization predicts psychological adjustment and quality of life in children and adolescents with a facial difference. Journal of Pediatric Psychology, 38, 162-172. https://doi.org/10.1093/jpepsy/jss 106

McVee, M. B., Dunsmore, K., \& Gavelek, J. R. (2005). Schema theory revisited. Review of Educational Research, 75,531-566. https://doi.org/10.3102/0034654 3075004531

Murray, J. C. (2002). Gene/environment causes of cleft lip and/or palate. Clinical Genetics, 61, 248-256. https://doi.org/10.1034/j.1399-0004.2002.610402.x

Natsume, N., Kawai, T., Ogi, N., \& Yoshida, W. (2000). Maternal risk factors in cleft lip and palate: Case control study. The British Journal of Oral \& Maxillofacial Surgery, 38, 23-25. https://doi.org/10.1054/ bjom. 1999.0133

Patrick, D. L., Topolski, T. D., Edwards, T. C., Aspinall, C. L., Kapp-Simon, K. A., Rumsey, N. J., Strauss, R. P., \& Thomas, C. R. (2007). Measuring the quality of life of youth with facial differences. The Cleft Palate-Craniofacial Journal, 44, 538-547. https://doi.org/10.1597/06-072.1
Pierpont, E. I., Semrud-Clikeman, M., \& Pierpont, M. E. (2017). Variability in clinical and neuropsychological features of individuals with MAP2K1 mutations. American Journal of Medical Genetics Part A, 173, 452-459. https://doi.org/10.1002/ajmg.a.38044

Rahman, J., \& Rahman, S. (2019). The utility of phenomics in diagnosis of inherited metabolic disorders. Clinical Medicine, 19, 30-36. https://doi.org/ 10.7861/clinmedicine.19-1-30

Ratner, C. (1999). Three approaches to cultural psychology: A critique. Cultural Dynamics, 11, 7-31. https://doi.org/10.1177/092137409901100102

Roberts, R. M., \& Shute, R. H. (2012). A prospective study of coping and adjustment in adolescents with craniofacial conditions. Children's Health Care, 41, 111-128. https://doi.org/10.1080/0273961 5.2012.657031

Robinson, E., Rumsey, N., \& Patridge, J. (1996). An evaluation of the impact of social interaction skills training for facially disfigured people. British Journal of Plastic Surgery, 49, 281-289. Retrieved from http://www.jprasurg.com/article/S0007-1226 (96)90156-3/pdf

Romitti, P. A., Sun, L., Honein, M. A., Reefhuis, J., Correa, A., \& Rasmussen, S. A. (2007). Maternal periconceptional alcohol consumption and risk of orofacial clefts. American Journal of Epidemiology, 166, 775-785. https://doi.org/10.1093/aje/kwm146

Roosenboom, J., Hens, G., Mattern, B. C., Shriver, M. D., \& Claes, P. (2016). Exploring the underlying genetics of craniofacial morphology through various sources of knowledge. BioMed Research International, ID 3054578. https://doi.org/10.1155/2016/3054578

Rowland, M. P., \& Bell, E. C. (2012). Measuring attitudes of sighted college students towards blindness. Journal of Blindness Innovation and Research, 2. https://doi.org/10.5241/2F2-24

Rumsey, N., \& Harcourt, D. (2005). The psychology of appearance. London: Oxford University Press.

Shaw, G. M., Lammer, E. J., Wasserman, C. R., O’Malley, C. D., \& Tolarova, M. M. (1995). Risks of orofacial clefts in children born to women using multivitamins containing folic acid periconceptionally. Lancet, 346, 393-396. https://doi. org/10.1016/S0140-6736(95)92778-6

Snyder, K. A., \& Pearse, W. (2010). Crisis, social support, and the family response: Exploring the narratives of young breast cancer survivors. Journal of Psychosocial Oncology, 28, 413-431. https://doi. org/10.1080/07347332.2010.484830

Spinelli, C. G. (2004). Dealing with cancer in the classroom: The teacher's role and responsibilities. Teaching Exceptional Children, 36, 14-21. Retrieved from http://journals.sagepub.com/doi/abs/10.1177 /004005990403600402?journalCode=tcxa

Strobel, L., \& Renner, G. (2016). Quality of life and adjustment in children and adolescents with Moebius syndrome: Evidence for specific impairments 
in social functioning. Research in Developmental Disabilities, 53, 178-188. https://doi.org/10.1016/j. ridd.2016.02.005

Tickle-Degnen, L., \& Lyons, K. D. (2004). Practitioners' impressions of patients with Parkinson's disease: The social ecology of expressive mask. Social Science \& Medicine, 58, 603-614. https://doi. org/10.1016/S0277-9536(03)00213-2

Tolarova, M., \& Harris, J. (1995). Reduced recurrence of orofacial clefts after periconceptional supplementation with high-dose folic acid and multivitamins. Teratology, 51, 71-78. https://doi.org/10.1002/ tera. 1420510205

Topolski, T. D., Edwards, T. C., \& Patrick, D. L. (2005). Quality of life: How do adolescents with facial differences compare with other adolescents? The Cleft Palate-Craniofacial Journal, 42, 19-24. https:// doi.org/10.1597/03-097.3.1

Vygotsky, L. S. (1978). Mind in society. Cambridge, MA: Harvard University Press.

Warschausky, S., Kay, J. B., Buchman, S., Halberg, A., \& Berger, M. (2002). Health-related quality of life in children with craniofacial anomalies. Plastic and Reconstructive Surgery, 110, 409-414. Retrieved from https://insights.ovid.com/pubmed?pmid=12142651

Wilcox, A. J., Lie, R. T., Solvoll, K., Taylor, J., McConnaughey, D. R., Abyholm, F., Vindenes, H., Vollset, S. E., \& Drevon, C. A. (2007). Folic acid supplements and risk of facial clefts: National population based case-control study. British Medical Journal, 334, 464. https://doi.org/10.1136/bmj.39079.618287.0B

World Health Organization. (2003). Global registry and database on craniofacial anomalies: Report of a WHO registry meeting on craniofacial anomalies (3rd ed.). Bauru, Brazil: WHO.

Wyszynski, D. F., \& Beaty, T. H. (1996). Review of the role of potential teratogens in the origin of human nonsyndromic oral clefts. Teratology, 53, 309-317. https://doi.org/10.1002/(SICI)1096-9926 (199605)53:5<309::AID-TERA5>3.0.CO;2-W

Yoo, G. J., Aviv, C., Levine, E. G., Ewing, C., \& Au, A. (2010). Emotion work: Disclosing cancer. Support Care Cancer, 18, 205-215. https://doi.org/10.1007/ s00520-009-0646-y

Zebrowitz, L. A., \& Montepare, J. M. (2008). Social psychological face perception: Why appearance matters. Social and Personality Psychology Compass, 2, 1497-1517. https://doi.org/10.1111/j.17519004.2008.00109.x

Zulauf, C., Spinelli, T., \& Rosenberg, J. (2018). Advocating for the child: The role of pediatric psychology for children with cleft lip and/or palate. Plastic Surgical Nursing, 38, 114-120. https://doi. org/10.1097/PSN.0000000000000232 
Supplementary Table S1

Summary of studies examining interpersonal functioning of individuals with CFCs or similar medical conditions

\begin{tabular}{|c|c|c|c|c|}
\hline Study & Sample type & $N$ & Methodology & Summary of findings \\
\hline
\end{tabular}

Psychosocial functioning

Bemmels et al. Adolescents,

Eric Riklin,

Margaret S.

Andover,

Rachel A.

Annunziato and adults with a range 12-61 young adults, of CFCs, aged

Boltshauser,

Children, adoLudwig, Dietrich, \& Landolt (2003) lescents, and young adults with craniosynostosis, aged 2-26

Crerand, Sarwer, Kazak, Clarke, \& Rumsey (2017)

Edwards, Topolski, Kapp-Simon, Aspinall, \& Patrick (2011)

Adolescents with and without CFCs, aged $14-18$

Young adults with and without CFCs, aged 11-18, medical students, and
38 Participants completed in-person, video-recorded semistructured interviews that ranged in length from 30 to $90 \mathrm{~min}-$ utes.

30 Participants completed assessments examining neurological status, head shape, school performance, behavior, and QoL, as well as neuropsychological testing.

112 Case-control study examining the relationship between body image and QoL. Participants completed measures of QoL and body image. education students

Edwards et al. Adolescents (2005)

175 Participants viewed 1-minute video portrayals of positive and negative social skills and rated their perceptions of the actors' attributes using the FIRS.

61 Qualitative methods including semi- and young adults with a range of CFCs, aged 11-25, and parents of children with CFCs
Themes included undergoing surgery to reduce stigmatization, psychological and social effects of interventions, surgical outcome satisfaction, parental involvement in decision making regarding surgery, and recommendations for parents considering surgery for their children with CFCs. Participants highlighted the importance of health care teams advising patients and parents about treatment options.

Psychological adjustment, general intellectual performance, and QoL were found to be within normal limits. However, $40 \%$ of the sample reported repeated teasing by their peers, and the sample displayed lower scores for positive emotions and increased internalizing symptoms.

Body image and QoL in adolescents with CFCs are similar to their peers. Within both groups, greater body image disturbance was related to lower QoL. Adolescents with CFCs reported lower appearance investment and were more likely to report concerns about facial features. The two groups did not differ in QoL, body image disturbance, or satisfaction with appearance. structured, in-depth interviews and focus groups.
Those who portrayed negative social skills were rated more negatively than those who portrayed positive social skills. Only vignettes portraying negative social skills resulted in greater facial difference severity.

The authors determined seven themes from the study: coping, stigma and isolation, intimacy and trust, positive consequences, self-image, negative emotions, and surgery.

(Table S1 continues) 


\begin{tabular}{|c|c|c|c|}
\hline Study & Sample type & $N$ & Methodology \\
\hline $\begin{array}{l}\text { Fischer et al. } \\
(2014)\end{array}$ & $\begin{array}{l}\text { Adults with } \\
\text { Crouzon } \\
\text { syndrome and } \\
\text { adults without } \\
\text { a CFC, aged } \\
18-64\end{array}$ & 316 & $\begin{array}{l}\text { Participants com- } \\
\text { pleted questionnaires } \\
\text { assessing present } \\
\text { life situation, social } \\
\text { status, education, } \\
\text { employment, and } \\
\text { QoL. }\end{array}$ \\
\hline $\begin{array}{l}\text { Masnari et al. } \\
(2013)\end{array}$ & $\begin{array}{l}\text { Youth with } \\
\text { a visible } \\
\text { facial differ- } \\
\text { ence, aged } \\
9 \text { months to } \\
16 \text { years }\end{array}$ & 88 & $\begin{array}{l}\text { Participants com- } \\
\text { pleted measures } \\
\text { assessing psychologi- } \\
\text { cal adjustment and } \\
\text { HRQoL. }\end{array}$ \\
\hline
\end{tabular}

Patrick et al. Youth with (2007) facial differences, aged 11-18

Roberts

\& Shute (2012) with CFCs, aged 11-19, and their parents

Strobel

\& Renner

(2016)
Children and adolescents with MoS, aged 11-17, and their parents
307 Observational study in which participants completed questionnaires examining QoL, depression, self-rated health, and self-reported severity of their CFC.

80 Participants completed measures examining adjustment, coping strategies, and efficacy in response to CFC-related stressful situations at baseline and again 12 months later.

40 Participants completed measures assessing HRQoL, psychological adjustment, and the global, social, and emotional impact of MoS.
Summary of findings

Those with Crouzon syndrome were found to have lower levels of education, were less often married, less likely to have a partner, had fewer children of their own, had less experience of a sexual relationship, and lower social performance than matched controls. However, there was no difference between the groups regarding a general positive attitude of life and those with Crouzon syndrome displayed a wide range of abilities.

Psychological adjustment was found to be within normal limits. However, HRQoL of participants aged 7-16 was found to be impaired across several dimensions, including psychological well-being. Psychological adjustment and HRQoL were predicted primarily by perceived stigmatization such that children and adolescents with high levels of stigmatization were at greatest risk of psychological maladjustment and low HRQoL.

Youth with acquired facial differences reported higher scores on negative consequences and negative self-image domains than those with congenital facial differences. However, there were no differences between the groups in stigma, coping, and positive consequences domains of the QoL measure. Also, youth who rated their facial differences as more severe reported poorer QoL than youth who perceived their facial difference as mild or moderate.

Baseline coping variables were significantly related to adjustment both at baseline and at 12-month follow-up. However, coping and efficacy at baseline did not explain the variance in adjustment at 12 months, even after controlling for baseline adjustment.

In comparison with normative data, those with MoS had reduced QoL in regard to the "Friends" domain. Parents reported elevated levels of peer problems and selfreported data revealed abnormal levels in the "Peer Problems" domain. 29\% of participants reported feelings of anger when being stared at and wished they were not affected by MoS.
Social dysfunction in those with CFCs

(Table $S 1$ continues) 
Supplementary Table S1

(Table S1 continued)

\begin{tabular}{|c|c|c|c|}
\hline Study & Sample type & $N$ & Methodology \\
\hline $\begin{array}{l}\text { Topolski, } \\
\text { Edwards, } \\
\text { \& Patrick } \\
(2005)\end{array}$ & $\begin{array}{l}\text { Adolescents } \\
\text { with CFCs, } \\
\text { aged } 11-18\end{array}$ & 292 & $\begin{array}{l}\text { Compared self- } \\
\text { reported QoL. }\end{array}$ \\
\hline $\begin{array}{l}\text { Warschausky, } \\
\text { Kay, Buchman, } \\
\text { Halberg, } \\
\text { \& Berger } \\
(2002)\end{array}$ & $\begin{array}{l}\text { Children and } \\
\text { adolescents } \\
\text { with CFCs, } \\
\text { aged 5-18 }\end{array}$ & 54 & $\begin{array}{l}\text { A prospective study } \\
\text { in which primary } \\
\text { caregivers completed } \\
\text { questionnaires as- } \\
\text { sessing health and } \\
\text { HRQoL. }\end{array}$ \\
\hline
\end{tabular}

Eric Riklin,

Margaret S.

Andover,

Rachel A.

Annunziato
Hemmesch, Older adults Tickle-Degnen, from the \& Zebrowitz (2009) greater Boston area, aged 55-91

Tickle-Degnen \& Lyons (2004)

\section{Expert medi-}

cal professionals (i.e., practicing professionals) and novice medical professionals (i.e., students)

\section{Social stigma}

Bogart (2015)
Adolescents, aged 12-17, with MoS
58 Participants observed two randomized video clips of individuals with PD and rated the target individuals' social functioning. Observers' ratings were compared to questionnaires filled out by the target individuals prior to the taping of the videos.

80 Compared the impressions of both groups after they viewed one of six video excerpts of patients with PD with different levels of expressive masking (i.e., low, intermediate, and high masking).

\section{Focus groups.}

Those with CFCs displayed lower QoL than those without a chronic condition and tended to feel less safe in school and reported less satisfaction with peers.

Findings showed that when compared to normative data, those with CFCs display a significant association between perceived physical health and psychosocial adjustment. Results indicated greater health concerns in subjects with non-CL/P. Parents of children with CFCs seem to associate the physical and mental health of their children with behavioral issues, family functioning, and their own parental stress.

Observers expressed less interest in relationships with women with higher facial masking and judged them as less supportive. They also formed less accurate ratings of the social supportiveness and social strain of women than men, and higher masking decreased accuracy for ratings of strain. The authors suggest that these inaccurate impressions of individuals with PD and the reduced desire to interact with them could be related to social dysfunction among these individuals.

Both groups of practitioners incorrectly rated individuals with more limited facial expressions as less agreeable and less extraverted than those with less limited facial expressions.

Themes related to social stigma, lack of societal awareness, and resiliency were found to be associated with social functioning. Moreover, adolescents with MoS were more likely to experience bullying and social strain than previous research on adults with MoS.

(Table S1 continues) 


\begin{tabular}{|c|c|c|c|c|}
\hline Study & Sample type & $N$ & Methodology & Summary of findings \\
\hline $\begin{array}{l}\text { Feragen, } \\
\text { Borge, } \\
\text { \& Rumsey } \\
(2009)\end{array}$ & $\begin{array}{l}\text { Children, } \\
\text { aged 9-12, } \\
\text { born with } \\
\mathrm{CL} / \mathrm{P}\end{array}$ & 268 & $\begin{array}{l}\text { Cross-sectional } \\
\text { study examining } \\
\text { factors that might } \\
\text { affect psychosocial } \\
\text { resiliency (i.e., cogni- } \\
\text { tive, emotional, and } \\
\text { psychosocial func- } \\
\text { tioning, satisfaction }\end{array}$ & $\begin{array}{l}\text { Lower psychosocial resilience was as- } \\
\text { sociated with lower satisfaction with } \\
\text { appearance and more reported teasing or } \\
\text { staring. Greater social stigma and lower } \\
\text { satisfaction of appearance may be linked } \\
\text { to greater dissatisfaction of social experi- } \\
\text { ences and greater social maladjustment } \\
\text { due to lower resilience. }\end{array}$ \\
\hline
\end{tabular}

Social dysfunction in those with CFCs

$\begin{array}{ll}\text { Hunt, Bur- } & \text { Children } \\ \text { den, Hepper, } & \text { and young } \\ \text { Stevenson, } & \text { adults with } \\ \text { \& Johnston } & \text { and without } \\ (2006) & \text { CL/P, aged } \\ & 8-21\end{array}$

Rowland

\& Bell (2012)

Snyder

\& Pearse

(2010) lescent and young adult 16-26 who were di-

\author{
Sighted un- \\ dergraduate \\ and graduate \\ students, aged \\ 17-61, and \\ blind ado- \\ 564 Compared the \\ attitudes towards \\ blindness of sighted \\ university students \\ to those of blind \\ students.
} students, aged

Adult women agnosed with breast cancer, aged 18-40
273 Participants completed questionnaires assessing psychological functioning, satisfaction with appearance, and social functioning.

70 Semi-structured phone interviews.
Being teased or bullied was a significant predictor of poor psychological functioning, greater behavioral problems, and greater dissatisfaction with appearances. Having $\mathrm{CL} / \mathrm{P}$ was not predictive of these outcomes.

Results showed that greater exposure to those who are blind yields more positive attitudes about blindness. Compared to sighted students, blind students hold more positive attitudes about blindness.
Core support networks were found to be participants' families and participants received social support in the form of emotional, tangible, informational, and, newly identified, experiential support, or support provided by someone who has gone through similar illnesses.

Participants displayed good psychosocial adjustment and resiliency strategies, and experienced increased self-acceptance, social acceptance, and acceptance of TCS over time. However, barriers included social stigma and fitting in at school. Major themes from the interviews included balancing same vs. difference and the journey towards self and social acceptance.

Stigma and lack of societal awareness were two of the main themes affecting social functioning.

(Table S1 continues) 
Supplementary Table S1

(Table S1 continued)

\begin{tabular}{|c|c|c|c|c|}
\hline Study & Sample type & $N$ & Methodology & Summary of findings \\
\hline $\begin{array}{l}\text { Joachim } \\
\text { \& Acorn (2003) }\end{array}$ & $\begin{array}{l}\text { Adults, aged } \\
46-79, \text { with } \\
\text { scleroderma }\end{array}$ & 13 & Focus groups. & $\begin{array}{l}\text { The data revealed five themes: physical } \\
\text { manifestations, disclosure/non-disclosure } \\
\text { to others, living, being normal, and facing } \\
\text { the future. Participants felt stigmatized by } \\
\text { others because their disease was so rare } \\
\text { that others did not understand their dif- } \\
\text { ficulties or appearance and did not know } \\
\text { how to interact with them. }\end{array}$ \\
\hline
\end{tabular}

Eric Riklin,

Margaret S.

Andover,

Rachel A.

Annunziato

\section{Future interventions}

Bessell et al. Adults, aged

18-83, with

a range of

visible differ-

ences

Kapp-Simon,

McGuire,

Adolescents with CFCs,

Long, \& Simon aged 12-14 (2005)

Robinson, Young adults Ramsey, \& Patridge (1996) and adults with facial disfigurements, aged 17-75

Yoo, Aviv, Levine, Ewing, \& Au (2010)
Adult women, 176 In-depth qualitative aged 31-83, who had been diagnosed with breast cancer within the past 4 years interviews focused on self-disclosure and social support.
83 Participants were randomized to three experimental conditions (i.e., a computer-based intervention, a faceto-face intervention, and a control condition) and assessed at four time points (i.e., pre- and post-intervention, and 3- and 6-month follow-ups).

20 Participants were enrolled in either a 12-week social skills training program or a no-treatment control group.

64 Participants participated in a 2-day social interactions skills workshop.
Those in the face-to-face intervention and computer-based intervention displayed significant reductions in anxiety, depression, appearance-related distress, and fear of negative evaluations compared to those in the control group. All improvements were maintained at both follow-up time points, suggesting increased positive adjustment over time. Additionally, there was an improvement in body image QoL among those in the face-to-face intervention, but not the computer-based intervention.

Those in the treatment group showed significantly more improvement in social interactions than those in the no-treatment control group. Adolescents in the treatment group were three times more likely to engage in a conversation with their peers than they were before starting the group.

Results showed a significant decrease in anxiety, social avoidance, and social distress at 6-weeks post-workshop, as well as a significant increase in confidence in the company of strangers and about meeting new people at 6-weeks post-workshop. All of these findings were maintained at 6-months post-workshop.

Results indicated that these individuals engaged in various self-disclosing strategies, but all of the strategies involved emotional work including managing others' worries, protecting and soothing others, and educating or instructing others. The authors suggest that others who are not well educated about the treatment and consequences of cancer need to be educated about the nature of the cancer experience.

Note. CFC - craniofacial condition; QoL - quality of life; FIRS - First Impressions Rating Scale; CL/P - cleft lip and/or palate; ADHD - attention deficit hyperactivity disorder; HRQoL - health-related quality of life; PD - Parkinson's disease; TCS - Treacher Collins syndrome; MoS - Moebius syndrome. 